\title{
Production optimization by using integer linear programming under a practical approach
}

\section{Optimización de la producción mediante la utilización de la programación lineal entera bajo un enfoque práctico} VELARDE-CANTÚ, José Manuel†, LÓPEZ-ACOSTA, Mauricio, CHACARA-MONTES, Allán and
RAMÍREZ-CÁRDENAS, Ernesto

Instituto Tecnológico de Sonora, Mexico.

ID $1^{\text {st }}$ Author: José Manuel, Velarde-Cantú / ORC ID: 0000-0002-1697-8551

ID $1^{\text {st }}$ Coauthor: Mauricio, López-Acosta / ORC ID: 0000-0003-3728-9576, Researcher ID Thomson: X-4274-2019

ID $2^{\text {nd }}$ Coauthor: Allán, Chacara-Montes / ORC ID: 0000-0002-0567-0017

ID $3^{\text {rd }}$ Coauthor: Ernesto, Ramírez-Cárdenas / ORC ID: 0000-0002-5248-724X

DOI: $10.35429 / J M Q M .2020 .7 .4 .1 .7$

Received July 10, 2020; Accepted December 30, 2020

\section{Abstract}

This paper addresses the problem of production scheduling under a practical approach, which seeks to find out what would be the product mix to ensure the company to obtain the most useful, also requires that these combinations of products obtained from quickly and efficiently contributing thus to achieve lower costs associated with production. A specific mathematical model based on integer linear programming applied specifically to the product mix is presented, as well as the results obtained from the practical problem from the use of the model in integer linear programming, the use of the software and considering the own conditions of the problem addressed here.

Production scheduling, PL, Optimization, Product mix

\begin{abstract}
Resumen
El presente trabajo aborda el problema de la programación de la producción bajo un enfoque práctico, el cual busca encontrar cual sería la mezcla de productos que garantice a la empresa obtener la mayor utilidad, así mismo se requiere que estas combinaciones de productos se obtengan de manera rápida y eficiente coadyuvando así a lograr disminuir los costos asociados a la producción. Se presenta un modelo matemático especifico basado en programación lineal entera aplicado específicamente al de mezcla de productos, así mismo se muestra los resultados obtenidos del problema practico a partir de la utilización modelo en programación lineal entera, la utilización del software y considerando las condiciones propias del problema aquí abordado.
\end{abstract}

Programación de la producción, PL, Optimización, Mezcla de productos

Citation: VELARDE-CANTÚ, José Manuel, LÓPEZ-ACOSTA, Mauricio, CHACARA-MONTES, Allán and RAMÍREZCÁRDENAS, Ernesto. Production optimization by using integer linear programming under a practical approach. JournalMathematical and Quantitative Methods. 2020. 4-7:1-7.

\footnotetext{
$\dagger$ Researcher contributing as first author.
} 


\section{Introduction}

Currently, the implementation of tools based on hard methodologies that seek to make each area or process more efficient in an organization has been increasing, these tools are extremely important in the search for optimization in the different activities found in each process such as: warehouse, production, distribution, etc. as well as in the rest of the areas of the organization.

With the implementation of the operations research methodology, it is sought to verify the hypothesis based on information and numerical measurements as well as with the statistical analysis with which different patterns of behavior can be established considering the correct use of the organization's available resources. The decrease in inventory levels, satisfying demand in a timely manner, in production, manufacturing only what is necessary, making these adjustments will improve the levels of profit provided by the sales of the different products handled by the company (Pérez et al, 2017)

When making a decision it is always very important to have sufficient and quality information to help us decide on each problem that may arise in the company, that is why we need tools, methodologies that provide information in a systematic way and relevant to the system under study. Within these tools and methodologies you can find the entire linear programming, which is used in multiple reallife optimization problems, among which the problem addressed here is identified, which seeks to find the best combination of manufacturing products that satisfy each and every one of the conditions of the problem, those of available resources such as raw materials, labor, available time, with the main objective of maximizing the profits obtained from the sale of these products.

Considering that the problem faced here has been widely studied by a large number of authors and that the product mix optimization problem is known in the literature, this problem contemplates small variations compared to its original form, one of them would be production of whole units and would be given by the integer linear programming (PLE), another variation is to consider the production as continuous or the products to be produced are in bulk, etc.
The problem studied here is considered typical in the literature and its large study does not delimit the different and varied applications that it may have, a clear example can be seen in Krajewski et al., (2008) where they use this problem to model the programming of production with the objective of finding the product mix in a given period, in this modeling consider market demand restrictions and available resources. This type of application to this problem gives us the confidence to continue developing new mathematical models to search for optimal solutions.

The main objective of this research is to build a solution to the problem addressed in a systematic way that contributes to the increase in profits. What is expected is to develop an optimization model according to the available manufacturing resources, considering the conditions of its production system, thus achieving a valuable contribution in the optimization area by designing and / or establishing a mathematical model based on integer linear programming. according to the special characteristics of the analyzed system.

\section{Methodology}

In the literature there is a great variety of different techniques focused on the search for the solution to the problem analyzed here, one of them is the mixed integer linear programming proposed in the work of Knaien et al., (2016) which uses it with the main objective of minimizing the sum of total production costs considering in them those related to the maintenance of the machines as well as the effect of these in the total profit of the company

In Taebok et al., (2018) propose deterministic models to define the production scheduling where the producer wants to know the quantity to be manufactured of each product in each of the different machines, which have a greater capacity than the demand. and where it is necessary to define the combination of machines to be used that optimizes operating costs

In Motta et al., (2016) presents a model based on mixed integer linear programming to find the solution to the production scheduling problem using different facilities. 
Among the objectives that this work seeks to achieve are those of meeting demand, reducing inventory costs and transportation costs, as well as increasing the use of different production facilities.

In the literature there are multiple applications of mixed integer linear programming, one of them addresses the problem of production scheduling in flexible job-shop environments where it considers the divisions of manufacturing jobs into smaller sublots, the mathematical model implemented allows to define if the division of the batches is necessary, considering an established measure of development and satisfying the set of restrictions given by the problem addressed. The proposal defines the start and end time for each manufacturing operation that is carried out on the sublots, in the same way it allocates these sublots to the appropriate production equipment (Novas, 2016).

In Capitanescu et al., (2017) the use of heuristic techniques can be found, which are widely used for the search for the solution for this type of problems, in this work the author proposes a special algorithm using a hybrid evolutionary method with the main objective of efficiently solving the problem of production scheduling under a bi-objective approach.

In Ortiz et al. (2015), an application of the theory of constraints based on linear programming can be observed to solve the problem of production programming, where through the identification of the different restrictions and the appropriate approach of the mathematical model it helps to define the mix of products to be manufactured that maximizes profit. Another application of the theory of constraints to the production scheduling problem can be found in Romero et al. (2019), where he uses this technique to achieve an improvement in the performance of the production system by determining the quantities to be manufactured of each product and the production sequence in the company.
In the work presented by Silva et al., (2017), concentrates a great variety of optimization techniques applied to the problem of production scheduling, performs a classification in two groups for these models, group one in deterministic and group two in stochastics, in the first they used exact solution techniques such as linear programming, mixed integer linear programming, and branching and boundary algorithms, for those of the second group they used approximation methods and stochastic programming, they also mention in their review that the $82 \%$ of the authors used deterministic models, which provides evidence of a notable growth in the use of exact solution techniques.

Based on an extensive analysis of methods and tools used in the literature, the decision was made to apply integer linear programming (PLE) as the best option to meet the objectives sought by the company, in the same way the software solver the which is found in the add-ins option in Excel, that is, due to its great ease of understanding and applying it. While it is true that the methodology to be used is an exact solution search technique which on some occasions may present some disadvantages due to the size of the problems, although for this particular case it does not present this disadvantage, that is, because the the problem is considered small, that is why it will help us find the solution quickly and efficiently, that is, it will provide us with the optimal solution. In contrast to heuristic programming techniques, which help us to find a solution when the problem is very large or when the search for this solution takes too long, for our practical case the use of evolutionary algorithms was not necessary since the model the mathematical used and the size of the problem favored the use of techniques based on exact algorithms, thus helping the company to have a quick, efficient solution that guarantees the maximum return on its profits.

The mathematical model based on PLE was implemented specifically applied to the product mix problem, this is because it currently does not have a methodology that systematically provides the different quantities to be produced of each item that allow the company to maximize its profits. 
The different parameters, indices and variables used in the model are defined to later define the objective function as well as the set of restrictions that the problem contemplates. The following section presents the mathematical model based on PLE applied to the practical problem addressed in this work.

\section{Mathematical model}

Indices:

i: Index used to identify the process of production $i \in\{1, \ldots, m\}$

$j:$ Index used to identify each type of products to be manufactured $j$

$$
\in\{1, \ldots, n\}
$$

Parameters:

m: Maximum number of processes used on the production line

$n$ : Maximum number of products to manufacture

Pij: Time in minutes used in the process $i$ to manufacture product $j$

Ti: Total time in minutes available to day in each process $i$

Dj: Minimum daily demand to produce of each product $j$

Gj: Profit of each product $j$

Decision variable:

$X_{j}$ : Amount of product $j$ to be produced per day

Objective Function:

$$
F . O \operatorname{Max} Z=\sum_{j=1}^{n} G_{j} X_{j}
$$

Equation 1. Objective function which calculates the maximum profit with the product mix

Subject to:

$\sum_{j=1}^{n} P_{i j} X_{j} \leq T_{i} \forall \mathrm{i} \in\{1, \ldots, \mathrm{m}\}$

Equation 2. Calculate not to exceed the times available in each process for the manufacture of the products.

$\sum_{j=1}^{n} X_{j} \geq D_{j}$

Equation 3. It guarantees us to meet the minimum demand for each type of product manufactured.
December 2020 Vol.4 No.7 1-7

$$
\begin{aligned}
& 6 X_{j-1}-X_{j}=0 \quad \forall j \in\{3\} \\
& X_{j-1}-X_{j}=0 \quad \forall j \in\{9\} \\
& 2 X_{j-2}-X_{j}=0 \quad \forall j \in\{10\}
\end{aligned}
$$

Equations 4, 5 and 6 are production restrictions according to the types of products to be manufactured

$X_{j} \geq 0, \forall j \in\{1, \ldots, n\}$, entera

Equation 7, establishes the non-negative and integer variables for this model.

\section{Results}

In this research work, the problem of production scheduling is considered, specifically that of product mix, for which a mathematical model based on PLE was developed in which it is sought to solve the central research hypothesis.

The results obtained with this investigation define the values of the decision variables considered in the model, as well as compliance with the series of restrictions imposed by the problem addressed that together form the optimal solution to the practical problem.

The results obtained from the problem under study are presented, which should show the optimal values of the variables that maximize the profits of the company. For this, relevant data of the problem were considered, which were obtained considering the needs and demands of the company where the study was carried out. 
The data used to find the solution to the real problem are: 10 different products to be manufactured were taken into account, a total of 15 manufacturing processes were defined through which each product must pass, the company works two 8-hour shifts daily which gives us a total of 960 minutes in both shifts, tables 1 and 2 show the times required to use each manufacturing process for each product, these times were obtained directly from the engineering department where the standard times are considered of each manufacturing process of each of the products considered in the study, in table 3 you can see the minimum demand that each of the products has, which must be satisfied daily, as well as the expected profit of each one of the products which is obtained from the difference between the sale price and the production cost associated with each of them, in table 4 you can see e 1 total time available in minutes for each production process.

\begin{tabular}{|c|c|c|c|c|c|}
\hline \multirow{2}{*}{$\begin{array}{c}\left\{\boldsymbol{P}_{\boldsymbol{i j}}\right\} \\
\{\boldsymbol{i}\}\end{array}$} & \multicolumn{5}{|c|}{$j$} \\
\hline & 1 & 2 & 3 & 4 & 5 \\
\hline 1 & 0.4 & 0.18 & 0.12 & 0.3 & 0.24 \\
\hline 2 & 1 & 0.45 & 0.3 & 0.75 & 0.6 \\
\hline 3 & 1.4 & 0.63 & 0.42 & 1.05 & 0.84 \\
\hline 4 & 1.4 & 0.63 & 0.42 & 1.05 & 0.84 \\
\hline 5 & 1.8 & 0.81 & 0.54 & 1.35 & 1.08 \\
\hline 6 & 1.6 & 0.72 & 0.48 & 1.2 & 0.96 \\
\hline 7 & 1.2 & 0.54 & 0.36 & 0.9 & 0.72 \\
\hline 8 & 0.6 & 0.27 & 0.18 & 0.45 & 0.36 \\
\hline 9 & 1.2 & 0.54 & 0.36 & 0.9 & 0.72 \\
\hline 10 & 0.8 & 0.36 & 0.24 & 0.6 & 0.48 \\
\hline 11 & 1 & 0.45 & 0.3 & 0.75 & 0.6 \\
\hline 12 & 1.8 & 0.81 & 0.54 & 1.35 & 1.08 \\
\hline 13 & 1.6 & 0.72 & 0.48 & 1.2 & 0.96 \\
\hline 14 & 2.4 & 1.08 & 0.72 & 1.8 & 1.44 \\
\hline 15 & 1.8 & 0.81 & 0.54 & 1.35 & 1.08 \\
\hline
\end{tabular}

Table 1 Work times in each process $\{i\}$ per product $\{j\}$ in minutes $\left\{\mathrm{P}_{\mathrm{ij}}\right\}$

\begin{tabular}{|r|r|r|r|r|r|}
\multicolumn{1}{c}{$\begin{array}{l}\left\{P_{i j}\right\} \\
\{\boldsymbol{i}\}\end{array}$} & \multicolumn{1}{c}{$\mathbf{6}$} & \multicolumn{1}{c}{$\mathbf{7}$} & \multicolumn{1}{c|}{$\mathbf{8}$} & \multicolumn{1}{c|}{$\mathbf{9}$} & \multicolumn{1}{c|}{$\mathbf{1 0}$} \\
\hline 1 & 0.32 & 0.26 & 0.18 & 0.2 & 0.24 \\
\hline 2 & 0.8 & 0.65 & 0.45 & 0.5 & 0.6 \\
\hline 3 & 1.12 & 0.91 & 0.63 & 0.7 & 0.84 \\
\hline 4 & 1.12 & 0.91 & 0.63 & 0.7 & 0.84 \\
\hline 5 & 1.44 & 1.17 & 0.81 & 0.9 & 1.08 \\
\hline 6 & 1.28 & 1.04 & 0.72 & 0.8 & 0.96 \\
\hline 7 & 0.96 & 0.78 & 0.54 & 0.6 & 0.72 \\
\hline 8 & 0.48 & 0.39 & 0.27 & 0.3 & 0.36 \\
\hline 9 & 0.96 & 0.78 & 0.54 & 0.6 & 0.72 \\
\hline 10 & 0.64 & 0.52 & 0.36 & 0.4 & 0.48 \\
\hline 11 & 0.8 & 0.65 & 0.45 & 0.5 & 0.6 \\
\hline 12 & 1.44 & 1.17 & 0.81 & 0.9 & 1.08 \\
\hline 13 & 1.28 & 1.04 & 0.72 & 0.8 & 0.96 \\
\hline 14 & 1.92 & 1.56 & 1.08 & 1.2 & 1.44 \\
\hline 15 & 1.44 & 1.17 & 0.81 & 0.9 & 1.08 \\
\hline
\end{tabular}

Table 2 Work times in each process $\{\mathrm{i}\}$ per product $\{\mathrm{j}\}$ in minutes $\left\{\mathrm{P}_{\mathrm{ij}}\right\}$

\begin{tabular}{r|r|r|}
\hline \multicolumn{1}{|r|}{$\boldsymbol{X}_{\boldsymbol{j}}$} & \multicolumn{1}{c|}{$\mathbf{G} \boldsymbol{j}$} & \multicolumn{1}{c|}{$\mathbf{D j}$} \\
\hline 1 & 20099 & 4 \\
\hline 2 & 9300 & 6 \\
\hline 3 & 2505 & 6 \\
\hline 4 & 14099 & 4 \\
\hline 5 & 8700 & 6 \\
\hline 6 & 9000 & 5 \\
\hline 7 & 13200 & 6 \\
\hline 8 & 5100 & 6 \\
\hline 9 & 3299 & 6 \\
\hline 10 & 1579.8 & 6 \\
\hline
\end{tabular}

Table 3 Gain $\{\mathrm{Gj}\}$ and minimum demand $\{\mathrm{Dj}\}$ for each type of product $\{\mathrm{Xj}\}$

\begin{tabular}{|r|r|}
\hline \multicolumn{1}{|c|}{ Process $\{\boldsymbol{i}\}$} & \multicolumn{1}{c|}{$\boldsymbol{T} \boldsymbol{\}}$} \\
\hline 1 & 19.2 \\
\hline 2 & 48 \\
\hline 3 & 67.2 \\
\hline 4 & 67.2 \\
\hline 5 & 86.4 \\
\hline 6 & 76.8 \\
\hline 7 & 57.6 \\
\hline 8 & 28.8 \\
\hline 9 & 57.6 \\
\hline 10 & 38.4 \\
\hline 11 & 48 \\
\hline 12 & 86.4 \\
\hline 13 & 76.8 \\
\hline 14 & 115.2 \\
\hline 15 & 86.4 \\
\hline
\end{tabular}

Table 4 Available time $\{\mathrm{Ti}\}$ to manufacture in each process $\{\mathrm{i}\}$

The results obtained with the EXCEL SOLVER software are presented below, which suggested that it is necessary to consider that the decision variables take the following values, see Table 5 in order to maximize profit.

\begin{tabular}{|r|r|}
\multicolumn{1}{|r|}{$\boldsymbol{X}_{\boldsymbol{j}}$} & $\begin{array}{r}\text { Value obtained by the Optimizer in units } \\
\text { to produce }\end{array}$ \\
\hline 1 & 7 \\
\hline 2 & 6 \\
\hline 3 & 36 \\
\hline 4 & 4 \\
\hline 5 & 6 \\
\hline 6 & 5 \\
\hline 7 & 6 \\
\hline 8 & 6 \\
\hline 9 & 6 \\
\hline 10 & 12 \\
\hline
\end{tabular}

Table 5 Solution obtained through the Excel Solver 
It can be observed (Table 5) the different values for the decision variables, these values show that for product 1 we must produce 7 units, for product 2 we must produce 6 , for product 3 we must produce 36 and so on until reaching to product 10 which must have a production of 12 units per day in order to obtain a maximum profit of 588820.6 pesos per day for the production and sale of the products manufactured by the company.

\section{Acknowledgments}

The work team thanks all the participants for their interest and collaboration during the data collection. Thanks also to the university (Instituto Tecnológico de Sonora) and the company for their support and the facilities for the development of the project; This publication has been financed with resources from PROFEXCE 2020.

\section{Conclusions}

It can be seen that thanks to the correct implementation of the mathematical model based on PLE applied to the production scheduling problem specifically to the product mix problem in this company, it helped to find a solution that met all the restrictions, thereby maximizing profits. Likewise, through this, it was possible to improve the use of available resources to produce.

It was also possible to establish a methodology that provides the company with a solution to the problem addressed in a systematic way by defining the amount of products that must be produced per day, considering that currently the company does not use any methodology that helps define the production results. Presented here are even more relevant since it provides this product mix through a methodology based on a quantitative method, which ensures that we have sufficient and quality information to make the best decision that helps the company find the maximum profit considering the use of available resources such as: capital, availability of labor and raw materials as well as the conditions of the problem addressed.

\section{References}

Capitanescu F., Marvuglia A., Benetto E., Ahmadi A., Tiruta L. (2017). Linear programming-based directed local search for expensive multi-objective optimization problems: Application to drinking water production plants. European Journal of Operational Research, 262(1), Issue 1, 322-334. https://doi.org/10.1016/j.ejor.2017.03.057

Hnaien F., Yalaoui F., Mhadhbi A., and Nourelfath M. (2016) A mixed-integer programming model for integrated production and maintenance, IFAC-PapersOnLine. 49(12), 556-561.

https://doi.org/10.1016/j.ifacol.2016.07.694

Krajewski, Lee J; Ritzman, Larry P. \& Malhotra, Manoj K. (2008). Administración de operaciones. México: Pearson Educación.

Motta C., Da Silva M., Bressan M., Almada B., (2016). Mathematical programming-based approaches for multi-facility glass container production planning. Computers \& Operations Research. 74 (1), 92-107. https://doi.org/10.1016/j.cor.2016.02.019

Novas, Juan M. (2016). Modelo MILP para la programación de la producción en ambientes job-shop flexibles con división de lotes. Iberoamerican Journal of Industrial Engineering, 8(16), 56-72.

Ortiz Triana, Viviana K., Caicedo Rolón, Álvaro Jr. (2015). Procedimiento para la programación y control de la producción de una pequeña empresa. Revista Ingeniería Industrial. 14 (1), 89-104.

Pérez Rodríguez, M. E. (2017). Impacto de la toma de decisiones basada en los modelos de investigación de operaciones en la dirección de proyectos de ingeniería para el sector privado. barranquilla. Secretaria de Economia. (s.f.). Secretaria de minería.

Romero Rojas, J. D., Ortiz Triana, V. K., Caicedo Rolón, A. J., (2019). La Teoría de Restricciones y la Optimización como Herramientas Gerenciales para la Programación de la Producción. Una Aplicación en la Industria de Muebles. Revista de métodos cuantitativos para la economía y la empresa. 27 (1), 74-90. 
Silva Rodríguez, Julián, Díaz Cárdenas, Camilo, Galindo Carabalí, Julián. (2017). Herramientas cuantitativas para la planeación y programación

de la producción: estado del arte. Ingeniería Industrial. Actualidad y Nuevas Tendencias, 5(18), 99-114.

Taebok Kim and Christoph H.Glock, Production planning for a two-stage production system with multiple parallel machines and variable production rates. International Journal of Production Economics. 196(1), 284-292.

https://doi.org/10.1016/j.ijpe.2017.11.018. 